\title{
Editorial: Literatura Sapiencial e a sua atualidade
}

\author{
Editorial: \\ Sapiential Literature and its relevance
}

\author{
Leonardo Agostini Fernandes
}

Prezados leitores e leitoras, a Revista Atualidade Teológica, com grata satisfação, apresenta o segundo exemplar deste ano, no qual oferece um dossiê com seis relevantes contribuições sobre a literatura sapiencial bíblica e a sua atualidade. $\mathrm{O}$ presente número contém, ainda, mais três artigos: um de índole bíblica e outros dois de índole teológico-pastoral. Assim, a ATeo preza e mantém o seu compromisso em função da sua missão: oferecer um espaço necessário e privilegiado para a comunidade acadêmico-científica propor os resultados dos estudos relacionados às áreas bíblica e teológico-pastoral.

Alegra-nos dizer que este número é, particularmente, significativo, porque coincide com a comemoração dos 1600 anos da morte de São Jerônimo (30/09/420-2020), visto e aceito, por muitos, como patrono e exemplo dos que se dedicam à Sagrada Escritura. Sabe-se que, no tocante à literatura sapiencial, entre os anos 382-384, a pedido do Papa São Dâmaso (366-384), São Jerônimo fez, estando em Roma, a revisão da tradução dos Quatro Evangelhos e do Saltério a partir da Septuaginta. Contudo, já instalado em Belém da Judeia, entre os anos 393-405, fez uma nova tradução do Saltério e dos "livros de Salomão" a partir da língua hebraica.

Pouco se sabe sobre os últimos dias de São Jerônimo. Segundo a tradição, foi sepultado entre as ruínas próximas da sua habitação em Belém. $\mathrm{Na}$ alta Idade Média, passou a ser venerado em uma fantástica iconografia, aparecendo não só em vestes cardinalícias, mas também com poucas vestes, idoso e ao lado de um crânio, de um leão amansado ou, ainda, entre feras pacificadas. Cenas que, certamente, buscaram retratar as diferentes fases 
da sua vida e os progressos espirituais que alcançou como grande sábio, estudioso da Bíblia e asceta.

Por seus inegáveis méritos, São Jerônimo figura como uma das quatro colunas que sustentam a vida da Igreja. Aparece como representante da Sagrada Escritura, ao lado de Santo Ambrósio, representante da Pastoral; de Santo Agostinho, representante da Filosofia e da Teologia; e de São Gregório Magno, representante da Liturgia. Por tudo isso, São Jerônimo é considerado um erudito entre os escritores latinos da antiguidade cristã, característica que fez dele, por sua vasta produção literária e intelectual, um exemplo ideal do estudioso da Sagrada Escritura e da Teologia. Nesse exemplo, por sua maestria, se inspiram os articulistas.

Portanto, o presente número da ATeo, dedicando um dossiê à literatura sapiencial, permite-nos refletir sobre inúmeros temas relacionados à vida e às instituições humanas que, do ponto de vista antropológico, são fundamentais para o estudo bíblico-teológico. De fato, a sabedoria, presente na Sagrada Escritura, tem como princípio e fonte vital o temor de Deus (Pr 1,7; 9,10; Eclo 1,14). Logo, a capacidade humana para adquirir ciência e conhecimentos práticos, seja por indução como por dedução, pressupõe a divina iluminação, sem a qual não pode chegar à verdade e às sínteses, considerando só a análise dos acontecimentos. Então, a sabedoria não é apenas fruto de reflexão e de experiências, mas é, sobretudo, uma questão de fé que não entorpece a mente e, por graça divina, a alarga e expande o saber para o infinito.

Diante de tal lógica, o dom da sabedoria, cultivado pelos sábios e mestres, permite ao ser humano observar e refletir sobre os vários aspectos da realidade e da existência, formulando sentenças, provérbios, exortações, ameaças e máximas, a fim de oferecer aos seus "filhos-discípulos" a via do êxito frente às seduções. Há, na sabedoria, algo pragmático!

Os sábios pertencem, ao lado dos sacerdotes e dos profetas, a uma classe cujo serviço, prestado ao povo de Deus, estava intimamente ligado ao dom do conselho, isto é, à arte do bem-viver que, requer e propõe a instrução, com justiça e disciplina, desde a mais tenra idade. Assim, a formação das gerações precisa ser ininterrupta, sem a qual, muito facilmente, o ser humano não consegue vencer os seus instintos e as bárbaras inclinações da sua natureza.

É certo, porém, que o gênero sapiencial não está limitado só aos livros sapienciais, mas são encontrados em outros livros do Antigo Testamento, inclusive está presente em várias partes do Novo Testamento. Graças a essa 
constatação, pois a Divina Sabedoria é fluente em toda a Bíblia, é possível adentrar em temas afins e provocar a reflexão intertextual.

No tocante à literatura sapiencial veterotestamentária, Davi e Salomão são aceitos como reis sábios. O primeiro canta a arte do bem-viver através dos Salmos. O segundo através das máximas, dos provérbios, dos cantos de amor e das várias sentenças que ajudam a regular a vida em âmbito pessoal e comunitário. Não à toa, 1 Rs 5,9-14 concede ao rei Salomão o título de rei sábio por excelência. Por isso, praticamente, todos os livros sapienciais do Antigo Testamento a ele foram associados.

A devida atenção, feita ao presente dossiê, permite encontrar diferentes e valiosos aspectos da literatura sapiencial bíblica, mostrando, facilmente, a sua ressonância e a sua aplicação em diferentes pontos da atualidade. A razão é simples: essa literatura apresenta uma disposição intelectual integrada, isto é, o conhecimento está orientado para o comportamento prático em nível pessoal, familiar, social e cultual, em função do bem, da justiça e da verdade.

Quando o assunto, por exemplo, é o sofrimento humano, sem dúvida o sábio Jó ocupa um relevante espaço na reflexão bíblico-teológica. Jó, por ser sábio e justo, não se conformou com a atribuição dos seus males a algum pecado cometido, pois a sua consciência era reta e em nada o acusava. A índole dos vários discursos, presentes no livro, representa diferentes pontos de vista sobre a teologia da retribuição, razão pela qual se nota que os "quatro amigos" buscaram defender muito mais a doutrina do que oferecer a Jó o que mais precisava na sua situação constrangedora: o consolo que atua como um bálsamo versado nas feridas.

Este equívoco cometido pelos "quatro amigos" de Jó, apesar de antigo, continua vivo, presente e ainda ocupa a concepção religiosa de muitas pessoas. Não é incomum, diante de determinados sofrimentos, ouvir alguém dizer: "Que mal eu fiz a Deus para merecer isso". É um drama existencial que toca a muitos seres humanos inocentes que acabam pagando pelo erro e egoísmo alheios. É a nefasta mancha das injustiças que se alastra e contamina o mundo.

Contudo, tal perspectiva pode e deve ser aprofundada e aprimorada a partir do evento da encarnação do Verbo Divino: Jesus de Nazaré, que, pela sua vida e pelo seu frutuoso ministério público, culminado no mistério pascal, passou a ser visto e professado como o Jó por excelência e o verdadeiro paradigma da paciência. O critério elementar é a sua obediência incondicional a Deus Pai, na unção do Espírito Santo, que revela o sentido do seu amor pela humanidade, permitindo aceitar e suportar o sofrimento e a morte como um 
meio capaz de fazer surgir e alimentar as virtudes da humildade, da prudência e da resiliência.

Graças a esse amor, o sofrimento e a morte podem ser redimensionados na direção do plano salvífico de Deus, mostrando que o pecado não teve, não tem e nunca terá a última palavra sobre a vida. A verdadeira teologia da retribuição, então, não se baseia na concepção do pecado, mas no amor que Deus revelou ter pelo ser humano e pela sua história. Assim, é possível compreender o sentido, a vocação e a missão do servo sofredor como vicária.

A consequência direta dessa inversão se verifica no pensamento sobre a teologia da retribuição, permitindo que o ser humano assuma, no confronto de Deus e do seu próximo, uma postura de esperança, baseada na experiência de salvação que se encontra cantada nos diferentes tipos de Salmos. Dado central em cada um deles é a fé em Deus fiel e providente. Por isso, nenhuma adversidade poderá invalidar o seu amor salvífico.

Este amor é o tema central que estabelece uma salutar relação sapiencial entre os dois Testamentos e mostra que é sábio quem conhece, profundamente, a si mesmo e sabe olhar, como o próprio Deus, para os demais e para o seu contexto vital, tirando as devidas consequências na verdade e na caridade. Por isso, dentre as matérias perscrutadas, refletidas e ensinadas pelos sábios, o silêncio é uma grande prerrogativa, pois permite ver no ordinário do humano o extraordinário da revelação divina. Então, a filosofia praticada pelo sábio bíblico é, por natureza, teológica e teleológica, porque direcionada para a plenitude da perfeição.

Isso permite perceber que em cada um dos escritos da literatura sapiencial bíblica, o fiel é colocado diante de posições que podem até ser contrastantes, impactantes ou aparentemente contraditórias, como, por exemplo, no livro de Eclesiastes, mas que, em última análise, apontam para o progresso da divina revelação, cujo clímax, segundo a perspectiva cristã, é a manifestação plena do amor de Deus, em Jesus Cristo, na plenitude do tempo (Gl 4,4).

No fundo, sobressai a importante relação entre a justiça e a misericórdia de Deus, elementos marcantes no livro de Sabedoria e em sua releitura do êxodo do Egito, sem as quais não haveria uma justa disposição capaz de ordenar a vida humana para uma certeza: o ímpio não levará a melhor sobre o justo, pois a vida deste está nas mãos de Deus (Sb 3,1). Esta relação atesta como Deus conduz a vida do ser humano de forma pedagógica e condizente com a sua natureza e as suas limitações. Sem esta verdade, não se adentraria 
no mistério inefável da encarnação da Segunda Pessoa da Santíssima Trindade como sabedoria de Deus.

Nos tempos atuais, marcados por individualismos, dicotomias, modismos e visões pessimistas da realidade, o presente número da "ATeo", que pertence ao PPG da PUC-Rio, oferece a ocasião de um grande aprendizado para docentes e discentes das áreas de teologia, ciências das religiões e afins. Em particular, no que se refere à promoção do diálogo capaz de suscitar o advento de uma época de renovação das estruturas sociais e eclesiais, voltadas para a educação e a formação humana integral. O estudo da literatura sapiencial, sem dúvida, pode abrir as portas da mente e do coração, movimento necessário para que a transformação do mundo ocorra a partir dos valores, das virtudes, da justiça e da prática do bem-comum.

Essa transformação, porém, necessita da primazia do serviço sobre todas as categorias de poder e de dominação, exatamente como vivido e ensinado por Jesus aos seus discípulos. Assim, por detrás da afirmação: "Não só de pão vive o homem mas de toda palavra que sai da boca de Deus" (Mt 4,4; Dt 8,3), encontra-se uma forte e vibrante motivação para a realização da missão dos fiéis no mundo: a de testemunhar que o valor da vida humana, em todas as suas fases, é uma prioridade a ser respeitada por qualquer área do saber.

Enfim, a dedicação e os estudos da Sagrada Escritura, quando são levados a sério, seguem um caminho irrenunciável: a fidelidade ao texto, reconhecendo a sua dupla autoria, Divino-Humana, e a fidelidade à voz do Magistério da Igreja que não está acima da Sagrada Escritura, mas é o guardião da sua verdade (DV 10-11): a salvação do ser humano, criado à imagem e semelhança de Deus, redimido e recriado em Jesus Cristo na unção e potência do Espírito Santo.

Que os esforços de tradução, de leitura, de compreensão e de interpretação da Sagrada Escritura sejam, na humildade das suas propostas, portadores de transformação sócio-eclesial, em particular em função da concretização da vontade de Jesus Cristo expressa, em oração ao Pai, na última ceia por sua Igreja: "que sejam um como nós somos um" (Jo 17,11).

\section{Referências bibliográficas}

BÍBLIA de Jerusalém. Nova ed. rev. e ampl. 2. impr. São Paulo: Paulus, 2003. CONCÍLIO VATICANO II. Constituição Dogmática Dei Verbum. 
Disponível em: <https://www.vatican.va/archive/hist_councils/ii_vatican council/documents/vat-ii_const_19651118_dei-verbum_po.html >. Acesso em: 06 ago. 2020.

\section{Leonardo Agostini Fernandes}

Doutor em Teologia Bíblica pela Pontificia Università Gregoriana, Roma Docente do Programa de Pós-graduação em Teologia da Pontifícia Universidade Católica do Rio de Janeiro Rio de Janeiro / RJ - Brasil E-mail: laf2007@puc-rio.br 